\title{
Gamifying a Serious Games Community
}

\author{
António Andrade, Carlos Vaz de Carvalho \\ GILT - Graphics, Interaction and Learning Technologies ISEP Porto, Portugal \\ cmc@isep.ipp.pt
}

\begin{abstract}
SEGAN (Serious Games Network) is a Community of Practice around the topic of Serious Games. It started in the scope of the Lifelong Learning programme with the intent of systematizing European approaches in this field, combining theory, research and practice. Like any other community, to be effective SEGAN needs to be dynamic, lively and continuously animated. Members must be involved, contribute, participate and feel they belong. This is not immediate as most community users are lurkers, that is, only receivers of the information. This article presents a strategy, based on gamification principles, planned to contribute to this involvement. Results so far have not been decisive but have allowed understanding better the dynamics of a Community.
\end{abstract}

Index Terms - serious games, gamification, community of practice, collaboration.

\section{Introduction}

Games are organized and ruled environments where players must overcome challenges and face opponents (real or game characters) to achieve victory. Failure to follow these rules implies a punishment or penalty. Games can offer an incredibly immersive and engaging environment where users 'learn by doing' and from their own errors in a controlled environment that is able also to improve teamwork, social skills, leadership and collaboration.

Serious Games focus on the design, development, use and application of games for purposes other than entertainment. Even if Education and training represent the main areas of application of Serious Games they have been used, with success, for health, research, emergency planning, advertisement and military purposes. The most striking effect in the use of Serious Games is an increased motivation and engagement. Their enjoyable context and interactivity enhance retention, cooperation and competition skills, strengthen social competences and the fun factor can continuously feed motivation into the learning process [1]. As such, Serious Games require specific design, recreating real scenarios through interactive and/or immersive environments.

Serious Games also relate with the development of Digital Literacy abilities. Today, more than ever, it is vital that everyone acquires a set of basic skills in information technology that will allow them to perform their tasks as citizens in an interconnected world. It is known that students who have used computers for several years perform better than average [2]. By contrast, those who don't have access to computers or who have been using computers for only a short time tend to lag behind their class year. However, the same study also makes an important note about gender discrimination: "Girls are less confident than boys in performing computer functions, especially high-level tasks such as programming or multi-media presentations. Girls also tend overall to use computers less frequently than boys." Another aspect related with digital literacy is the ability to use networked collaborative and social tools. This is a recent development of the Internet, the Social Web, that brings closer individuals in very different parts of the world but which is unsecure, fragmentary and chaotic. Serious Games can make a clear and definite contribution to this state of things by promoting the use of digital systems.

However, in spite of the existing evidence of success, there is still a limited use of Serious Games. This has mainly to do with social concerns and stereotypes about the relation of games and serious purposes. Other issues relate to physical and cost barriers, hardware and license cost, access (for online games), maintenance and support. But this limited use is also related to the lack of extended evidence of effective application. A series of initiatives has been conducted to solve this issue. The creation of a network of experts and practitioners in the area of Serious Games was one of these initiatives.

The Serious Game Network, or SEGAN, is a community of practice funded in the scope of the Life Long Learning program with the intent of systematizing "the European approaches to serious games, combining theory, research and practice in a way that promotes Europe as a major player in this field" [3]. In fact, more than half hundred projects funded by the European Commission under this thematic have been realized to date and this convergence seems now fundamental to increase the awareness of the benefits and impacts of serious games. The game and education industry are, more and more, looking seriously to the possibility of using this methodology to support training and education in general.

At the same time, SEGAN is looking to the future of Serious Games, including:

- The use of emerging communication platforms (PDA's, Smartphones, Tablet PCs, Game Consoles) that are already widely used by everyone.

- More flexible and customized content tailored to specific user profiles. The students' profile (previous knowledge, skill in handling information, personal preferences) should define the most suitable activities in a personalized learning environment.

- The integration of constructivist and connectivist principles in the pedagogical methodology to ensure a social networking approach.

- A change in educational practices, by making the student the centre of learning. 
The SEGAN community is mainly composed of academic researchers, game producers and Serious Games (SG) users but it is also open to any individual interested in the domain of $\mathrm{SG}$ and their implementation. SEGAN practice consists of the compilation of serious games resources in the online platform supporting the community as well as the open discussion of related topics, working towards annual publications on the design, development, delivery and evaluation of serious games. Face-to-face events are also part of the activities, namely an annual conference and summer school. Monthly open webinars are another important part of the community practice.

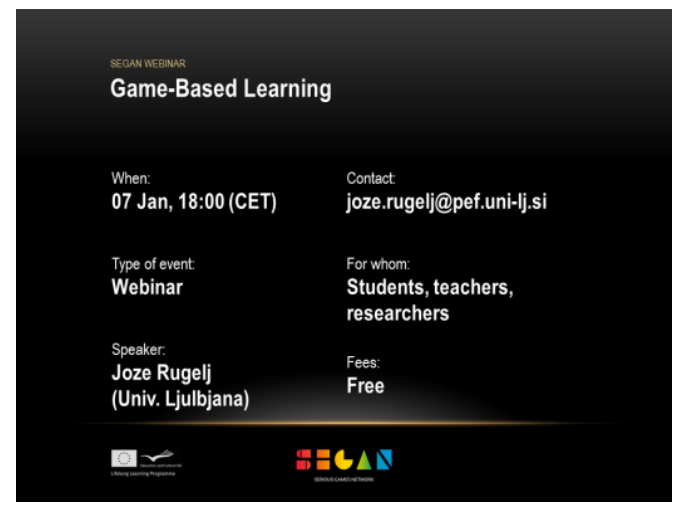

Fig. 1 SEGAN Webinar announcement

However, to keep SEGAN alive it was necessary to introduce new mechanisms to foster collaboration and participation from its members. The purpose of this article is precisely to present these mechanisms and the results obtained.

\section{Communities of Practice}

A community of practice $(\mathrm{CoP})$ is a "group of people who share a craft and/or a profession. The group can evolve naturally because of the members' common interest in a particular domain or area, or it can be created specifically with the goal of gaining knowledge related to their field" [4]. It is through the process of sharing information and experiences with the group that the members learn from each other, and have an opportunity to develop themselves personally and professionally. As such, a community of practice is often organically created, with as many objectives as members of that community. Typical activities engaged inside a community of practice relate to problem solving; information request; experience seeking; asset reuse; coordination and synergy; development discussion and knowledge mapping [5].

One of the most famous examples of such community happened within the Xerox company, where co-workers spontaneously organized a kind of internal support group and knowledge base, making common problem solving easier for other colleagues [6].

Wenger describes the evolution of a CoP as the result of the following factors [4]:

- Mutual Engagement: Firstly, through participation in the community, members establish norms and build collaborative relationships; this is termed mutual engagement. These relationships are the ties that bind the members of the community together as a social entity.

- Joint Enterprise: Secondly, through their interactions, they create a shared understanding of what binds them together; this is termed the joint enterprise. The joint enterprise is (re)negotiated by its members and is sometimes referred to as the 'domain' of the community.

- Shared Repertoire: Finally, as part of its practice, the community produces a set of communal resources, which is termed their shared repertoire; this is used in the pursuit of their joint enterprise and can include both literal and symbolic meanings.

This evolution, still according to Wenger, leads to the following structural characteristics:

- Domain: A domain of knowledge creates common ground, inspires members to participate, guides their learning and gives meaning to their actions.

- Community: The notion of a community creates the social fabric for that learning. A strong community fosters interactions and encourages the willingness to share ideas.

- Practice: While the domain provides the general area of interest for the community, the practice is the specific focus around which the community develops shares and maintains its core of knowledge.

Other authors also mention as fundamental factors:

- Social presence: the management of a community of practice often faces many barriers that inhibit individuals from engaging in knowledge exchange. Some of the reasons for these barriers are egos and personal attacks, large overwhelming CoP's, and time constraints [7]. Thus communicating with others within a community of practice involves creating social presence.

- Motivation: the will to share knowledge is critical to success in communities of practice. It is known that members are driven to become active participants in a $\mathrm{CoP}$ when they view knowledge as meant for the public good, a moral obligation and/or as a community interest [8]. Members of a community of practice can also be motivated to participate by using methods such as tangible returns (promotion, raises or bonuses), intangible returns (reputation, self-esteem) and community interest (exchange of practice related knowledge, interaction).

- Collaboration: collaboration is essential to ensure that communities of practice thrive. More seasoned colleagues and a higher educational level tend to foster a more collaborative culture [9].

Community membership is defined by the knowledge of the members. It is a social structure which widely promotes informal learning [11]. This term is an umbrella for all activities that somehow lead to the acquisition of knowledge and competences but happening outside schools or other training institutions (which are referred to as the formal system) 
[10]. The range of informal learning contexts is considerable and can be broken into different levels of learner awareness. Learning by socialization, for instance, is obviously not as intentional and systematic as self-driven learning [11].

The widespread access to the internet popularized a new paradigm, often referred to as the web 2.0. Amongst other things the web 2.0 is characterized by giving more emphasis to the relationships established between users and focusing on the diversity of content generated by each user. To support this, there was also a technical shift in the background by creating new collaboration tools (such as wikis) [12].

This evolution in the information technology field made it very interesting for the creation of virtual communities of practice [13]. Members are no longer restricted to being in the same physical space or even time zone to engage in common activities. Furthermore, the new tools available to use through the internet allow for easier organization and consumption of the shared repository.

However, one of the main problems in communities of practice is also emphasized by their virtualization: according to a 2009 research, $43 \%$ of the European internet users were then considered as "non-participative" [14]. Regular participation throughout the community fabric is a common drawback of virtual communities of practice, especially on their early life. Therefore ways to promote the dynamics and the activity of the community are required to ensure it becomes alive and stays that way.

\section{SEGAN Community and the use of Gamification}

The virtual SEGAN community started off as a Facebook group (available at http://www.facebook.com/groups/segan/). This had a few advantages such as the ease of use, the integration with such a popular leisure channel and the tendency for viral membership. Overall, this made participation in the group a natural flow in member's daily routines.

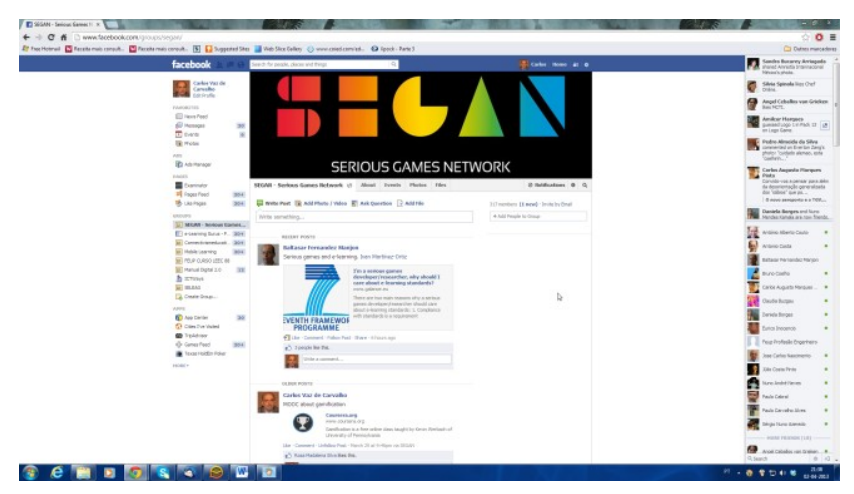

Fig. 2 SEGAN Facebook Group

However, using Facebook as the basis of the community also had negative implications which could harm its sustainability in the long term. On the top of the list were: the lack of administrative and organizational control; issues related to content ownership; the complete lack of independency from a community identity point of view; and, most of all, the single and dynamic flow of information which lead to members missing some important information.

Once the self-hosted community platform was ready (available at http://seriousgamesnet.eu/community), the migration was made in a way where users would see their previously created contents mapped to the new platform. Despite this, only part of the users decided to follow the community to the new platform and, with the exception of days surrounding webinars and meetings, the visits and participation dropped. This seemed to be the best timing to apply some gamification aspects to the SEGAN community.

One of the most common gamification definitions proposes it as the process of applying game mechanics to an interface as a mean to engage users [15]. This may consist of defining user achievements and badges, user points and leaderboards, challenges between users or virtual currencies (redeemable for goods or perks), for instance.

The most common critique to this process points the risk of turning game-like interaction into an end in itself, hence undermining content quality and missing out on the experiential and storytelling dimension of a product. In other words, it interprets rewards in a behaviorist way [15]. Another significant critique arose inside the SEGAN community pointing leaderboards as inhibiters of newcomers' participation. Other views highlight valid patterns to apply game mechanics to: validation of content (by peer review), completion of tasks (and progress assessment) and prizes [16]. Despite the criticism and skepticism, company success stories abound [17] and communities such as StackExchange have clearly benefited from such process before. The main question seems to boil down to the way gamification is implemented in the community.

Shannon Duffy indicates a few important ideas to temper motivation in a gamified community [18]. Firstly, it is important to define goals: what user actions indicate success? For instance, we could focus content quality over quantity. Rewards should of course be defined according to this priority. Secondly, using attainable achievements as alternative to cumulative user points is friendlier to newcomers. Finally, awarding MVP (Most Valuable Player) status to a select number of users may be beneficial: those will act as role models and, using special perks, may help curate and shape the community.

Many of the common gamification techniques seemed to make sense in SEGAN's case and would potentially inject some motivating fun factor. Content quality was a priority to SEGAN but before that it was important to engage members. Since overwhelming newcomers was another important factor taken into account, it was decided to would use both badges and user experience point (XP) leaderboards. As a general rule, $\mathrm{XP}$ tends to value quantity (and long term engagement) while achievement badges value quality.

Visit recency and frequency are commonly accepted engagement measurements [18]. Thus for each day the user logs into the platform he gets $1 \mathrm{XP}$. However, if a user 
manages to $\log$ in for thirty consecutive days, he/she will get the "Enthusiast" badge and the respective XP prize. Contributing contents is also rewarded. A blog post is awarded $10 \mathrm{XP}$, the double of the prize for a bookmark. If a user happens to create a blog post which receives more than twenty five comments she would be awarded the "Debate Starter" badge. Ideally this duality between achievements and XP allows for multiple ways to feel recognition inside the community. Content quality is provided by peer review in the simple form of up and down votes. Again, both the voter and the content author are awarded XP and eligible for specific achievement badges.

The data resulting from the community gamification is used throughout the platform to expose interesting users and content. The leaderboard (which stresses monthly gain over all time totals) and badges pages allow to assess overall community performance. Each user's profile is also enhanced with their total XP and badge listing. The "Top Rated Content" and "Top Influencers" (users who created most textual content, such as blogs and comments) blocks are also products of this process.

\section{Conclusions}

The Serious Game Network, or SEGAN, is a community of practice funded in the scope of the Life Long Learning program with the intent of systematizing European approaches to serious games, combining theory, research and practice.

Like in other CoPs, one of the main problems in SEGAN is the lack of regular participation of the members, especially on their early life. Therefore it was necessary to promote the dynamics and the activity of the community are required to ensure it became alive and stayed that way.

The use of gamification mechanisms seemed to be a good way to promote this increase of interaction. We learned that despite our focus on content creation (while setting the point awarding rules), to foster interaction between members through gamification one should balance the points awarded between the topic creator and the commentators. On the other hand, negative points and/or loosing part of the accumulated points, along with soft email reminders, might be a way to keep fading users engaged in the long term.

Ultimately, it's interesting to notice that although the gamification implementation received a rather cold reception in the community it clearly has contributed to the level of activity in the overall supporting platform.

\section{Acknowledgment}

This work has been sponsored by the European
Commission through its European Agency for Culture, Education, Audiovisual in the scope of the Lifelong Learning Programme, KA3 sub-programme, SEGAN network (ref. 519332-LLP-1-2011-1-PT-KA3-KA3NW)

\section{References}

[1] T. Susi, M. Johannesson and P. Backlund. "Serious games: An overview.", 2007.

[2] OECD, Study on digital learning resources as systemic innovation, [online]. Available at: http://www.oecd.org/edu/ceri/42214660.pdf

[3] Serious Games Network. (2012, November) "About SEGAN". [Online]. http://seriousgamesnet.eu/community/pages/view/1990/about-segan

[4] E. Wenger, "Communities of Practice: Learning, Meaning, and Identity", Cambridge University Press, 1998..

[5] J. Lave and E. Wenger, "Situated Learning: Legitimate Peripheral Participation": Cambridge: Cambridge University Press, 1991.

[6] J. E. Orr, "Narratives at work: story telling as cooperative diagnostic activity". In CSCW '86 Proceedings of the 1986 ACM conference on Computer-supported cooperative work, 1986.

[7] C. Tu, "The management of social presence in an online learning environment", International Journal on E-learning. April-June: 34-45, 2002 .

[8] A. Ardichvilli; V. Page,; T. Wentling, "Motivation and barriers to participation in virtual knowledge sharing in communities of practice", Journal of knowledge management 7 (1), 2003.

[9] K. Sveiby; R. Simon, "Collaborative climate and effectiveness of knowledge work - an empirical study", Journal of Knowledge Management 6 (5), 2007.

[10] European Union. (2013) European Commission, "Education and Learning”. [Online]. http://ec.europa.eu/education/lifelong-learningpolicy/informal_en.htm

[11] D. Shugurensky, "The Forms of Informal Learning: Towards a Conceptualization of the Field", University of Toronto, 2000.

[12] S. Leino and J. Ovaska, "A Survey on Web 2.0", University of Tampere, 2008.

[13] K. Lai, K. Pratt, M. Anderson and J. Stigter, "Literature Review and Synthesis: Online Communities of Practice". Dunedin, New Zealand, 2006. E. Riu and A. Jokisalo, "Informal learning in the era of Web 2.0", 2009.

[14] G. Zichermann and C. Cunningham, "Gamification by Design". O'Reilly, 2011.

[15] S. Deterding. "Pawned. Gamification and its Discontents." [Online]. http://www.slideshare.net/dings/pawned-gamification-and-itsdiscontents September, 2012

[16] T. Kelly. "Everything You'll Ever Need To Know About Gamification". [Online]. http://techcrunch.com/2012/11/17/everything-youll-ever-needto-know-about-gamification/ November, 2012

[17] G. Zichermann. "7 Winning Examples of Game Mechanics in Action". [Online]. http://mashable.com/2011/07/06/7-winning-examples-ofgame-mechanics-in-action/ July, 2011.

[18] S. Duffy, "4 Tips for Keeping Your Gamified Community Motivated". [Online]. http://mashable.com/2012/04/24/tips-motivating-gamifiedcommunity/ April, 2012. 